\title{
Early interventions to prevent psychosis: systematic review and meta-analysis
}

\author{
(c) (1) (8) OPEN ACCESS
}

\author{
Megan R Stafford systematic reviewer ${ }^{1}$, Hannah Jackson research assistant ${ }^{1}$, Evan Mayo-Wilson \\ senior research associate ${ }^{2}$, Anthony $\mathrm{P}$ Morrison professor of clinical psychology ${ }^{3}$, Tim Kendall \\ codirector National Collaborating Centre for Mental Health ${ }^{4}$
}

${ }^{1}$ National Collaborating Centre for Mental Health, Royal College of Psychiatrists, London, UK; ${ }^{2}$ Centre for Outcomes Research and Effectiveness, Research Department of Clinical, Educational and Health Psychology, University College London, London, UK; ${ }^{3}$ School of Psychological Sciences, University of Manchester, Manchester, UK; ${ }^{4}$ Sheffield Health and Social Care NHS Foundation Trust, Sheffield S10 3TH, UK

\begin{abstract}
Objective To determine whether any psychological, pharmacological, or nutritional interventions can prevent or delay transition to psychotic disorders for people at high risk.

Design Systematic review and meta-analysis.

Data sources Embase, Medline, PreMedline, PsycINFO, and CENTRAL were searched to November 2011 without restriction to publication status.

Review methods Randomised trials comparing any psychological, pharmacological, nutritional, or combined intervention with usual services or another treatment. Studies of participants with a formal diagnosis of schizophrenia or bipolar disorder were excluded. Studies were assessed for bias, and relevant limitations were considered in summarising the results.

Results 11 trials including 1246 participants and eight comparisons were included. Median sample size of included trials was 81 (range 51-288). Meta-analyses were performed for transition to psychosis, symptoms of psychosis, depression, and mania; quality of life; weight; and discontinuation of treatment. Evidence of moderate quality showed an effect for cognitive behavioural therapy on reducing transition to psychosis at 12 months (risk ratio 0.54 (95\% confidence interval 0.34 to 0.86$)$; risk difference $-0.07(-0.14$ to -0.01$)$. Very low quality evidence for omega-3 fatty acids and low to very low quality evidence for integrated psychotherapy also indicated that these interventions were associated with reductions in transition to psychosis at 12 months.

Conclusions Although evidence of benefits for any specific intervention is not conclusive, these findings suggest that it might be possible to delay or prevent transition to psychosis. Further research should be undertaken to establish conclusively the potential for benefit of psychological interventions in the treatment of people at high risk of psychosis.
\end{abstract}

\section{Introduction}

The incidence of probable psychosis in community surveys in the United Kingdom appears to be stable, at about five per 1000 adults.[1] [2] Schizophrenia is the most common form of psychosis and one of the leading causes of long term disability, [3] affecting about 25 million people worldwide. Schizophrenia disrupts social and family relationships, resulting in severe educational and occupational impairment, lost productivity, unemployment, physical illness, and premature mortality.[4] As a result, schizophrenia costs about $£ 55000$ ( $€ 67500 ; \$ 88$ 000) per person per year in the UK.[5]

Schizophrenia is usually preceded by a prodromal period lasting one to three years.[6] This period is characterised by a range of non-specific behavioural and psychological symptoms, functional deterioration, and by both attenuated positive symptoms and brief limited intermittent psychotic symptoms (BLIPS).[7] Among people at "ultra high risk" of psychosis, about $22 \%$ to $40 \%$ transition within 12 months.[8][9][10] Interventions that delay or prevent transition to psychosis from this prodromal syndrome could be clinically and economically important.

Antipsychotic drugs and family therapy could reduce the likelihood of relapse for established and first episode schizophrenia, and cognitive behavioural therapy (CBT) might reduce symptoms and hospital admission for people with schizophrenia.[11] Combining these treatments in an integrated strategy might add substantial clinical[12] and economic benefits[13] for people with psychosis and early schizophrenia. These interventions could prevent or delay the onset of psychosis and schizophrenia if delivered to people at high risk, and several trials have examined whether these interventions prevent 
transition from a high risk state to psychosis. A previous review of early interventions[14] found limited evidence about interventions to prevent psychosis, but the searches were conducted in 2009, and several studies conducted since then have been sufficiently large to change the review's conclusions. An updated review is needed to determine whether any interventions can prevent or delay transition to psychotic disorders.

\section{Methods \\ Eligibility criteria}

We evaluated the effect of any intervention (pharmacological, psychological, nutritional, or combination) for participants with prodromal symptoms. Included participants were judged to be at risk of developing psychosis on the basis on a clinical assessment identifying prodromal features. Studies including participants with a formal diagnosis of schizophrenia or bipolar disorder (including first episode psychosis) were excluded. Randomised controlled trials for people at risk and for participants with schizotypal disorders were included.

\section{Types of outcome measures}

The primary outcome was transition to psychosis. Secondary outcomes were symptoms of psychosis (total, positive, and negative), depression, and mania; quality of life; weight; and discontinuation. Analyses were conducted for outcomes measured within six months of randomisation, between six and 12 months of randomisation, and after 12 months of randomisation.

\section{Search strategy}

We searched Embase, Medline, PreMedline, PsycINFO, and CENTRAL from the inception of the databases to November 2011. Searches in Embase, Medline, PreMedline and PsycINFO were combined with a highly sensitive filter for randomised controlled trials. The search was initially developed in Medline before being translated for use in other databases. The box details the Medline search for groups at risk (web appendix 1 shows the full list of search terms used across databases). We also searched the reference lists of included studies, excluded studies, and previous reviews, and contacted study authors and experts.

\section{Assessment of bias}

Studies were assessed independently by two authors (MRS, HJ) using the Cochrane Collaboration risk of bias tool.[15]

Disagreements were discussed with a third author (EM-W) and resolved by consensus. Each study was rated for risk of bias owing to sequence generation; allocation concealment; blinding of participants, assessors, and providers; selective outcome reporting; and incomplete data. Risk of bias for each domain was rated as high (seriously weakens confidence in the results), low (unlikely to seriously alter the results), or unclear.

\section{Data management}

Data extraction and risk of bias assessments were completed using an Excel spreadsheet. We collected data for time points and measures, recruitment, inclusion and exclusion criteria, age, sex, setting, and location.

\section{Statistical analysis}

For continuous outcomes, we calculated the standardised mean difference, Hedges $g$.[16] For dichotomous outcomes, an overall risk ratio was calculated. All outcomes are reported with $95 \%$ confidence intervals. Overall effects were calculated using a random effects model. Continuous effects were weighted by the inverse of variance; dichotomous effects were weighted using the Mantel-Haenszel method.[17] [18]

Missing data were noted for each outcome. When dropout was not reported, we contacted the authors. If both primary and secondary outcomes reported data for completers as well as controlled for dropouts (for example, data imputed using regression methods), we used the data controlling for dropout. We conducted sensitivity analyses for the primary outcome (transition to psychosis) when studies reported data for completers only.

Statistical heterogeneity was assessed by visual inspection of forest plots, by performing the $\chi^{2}$ test (assessing the $\mathrm{P}$ value), and by calculating the $\mathrm{I}^{2}$ statistic,[19] [20] which describes the percentage of observed heterogeneity that would not be expected by chance. If the $\mathrm{P}$ value was less than 0.10 and $\mathrm{I}^{2}$ exceeded $50 \%$, we considered heterogeneity to be substantial.

Meta-analyses were conducted using RevMan.[21] Confidence in the results was assessed using the GRADE method,[22] which is a structured assessment of the quality of evidence attending to the following factors: risk of bias, inconsistency, indirectness, imprecision, and publication bias.

\section{Results}

\section{Trial flow}

Of 1913 potentially relevant citations, we retrieved 39 papers; of these, 18 were excluded as they did not meet our eligibility criteria (web appendix 2). The most common reason for exclusion was that the study was not a randomised controlled trial. Eleven randomised controlled trials reported in 21 published papers met all inclusion criteria (fig $1 \Downarrow$ ), and authors provided unpublished data for two of these.[23] [24]

\section{Study characteristics}

Eleven included trials assigned 1246 participants with a median sample size of 81 (range 51-288). The median of the mean ages was 21 years, and $710(57 \%)$ randomised participants were male. Eight studies[23][24][25][26][27][28][29][30] included participants meeting one or more of three operationally defined groups (attenuated psychotic symptoms, transient psychotic symptoms, trait and state risk factors). The first two groups were operationalised as scoring above a threshold on a screening instrument: the structured interview for prodromal symptoms, [9] the positive and negative symptom scale (PANSS)[31], the brief psychiatric rating scale (BPRS),[32] or the comprehensive assessment of at risk mental states (CAARMS).[33] One study included adults who met ICD-10 (international classification of diseases, 10th revision) [34] research criteria for schizotypal disorder,[35] two studies used the early recognition inventory (ERIraos),[36] with one study identifying participants in the early initial prodromal state[37] and one study not reporting the eligibility threshold used.[38] Table $1 \Downarrow$ lists characteristics of the included studies.

The 11 included studies made eight comparisons. Four trials compared CBT with supportive counselling and monitoring.[23] [25] [28] [29] Two trials compared risperidone and CBT with supportive counselling.[24] [30] One trial each compared risperidone and CBT with placebo and CBT,[24] olanzapine 


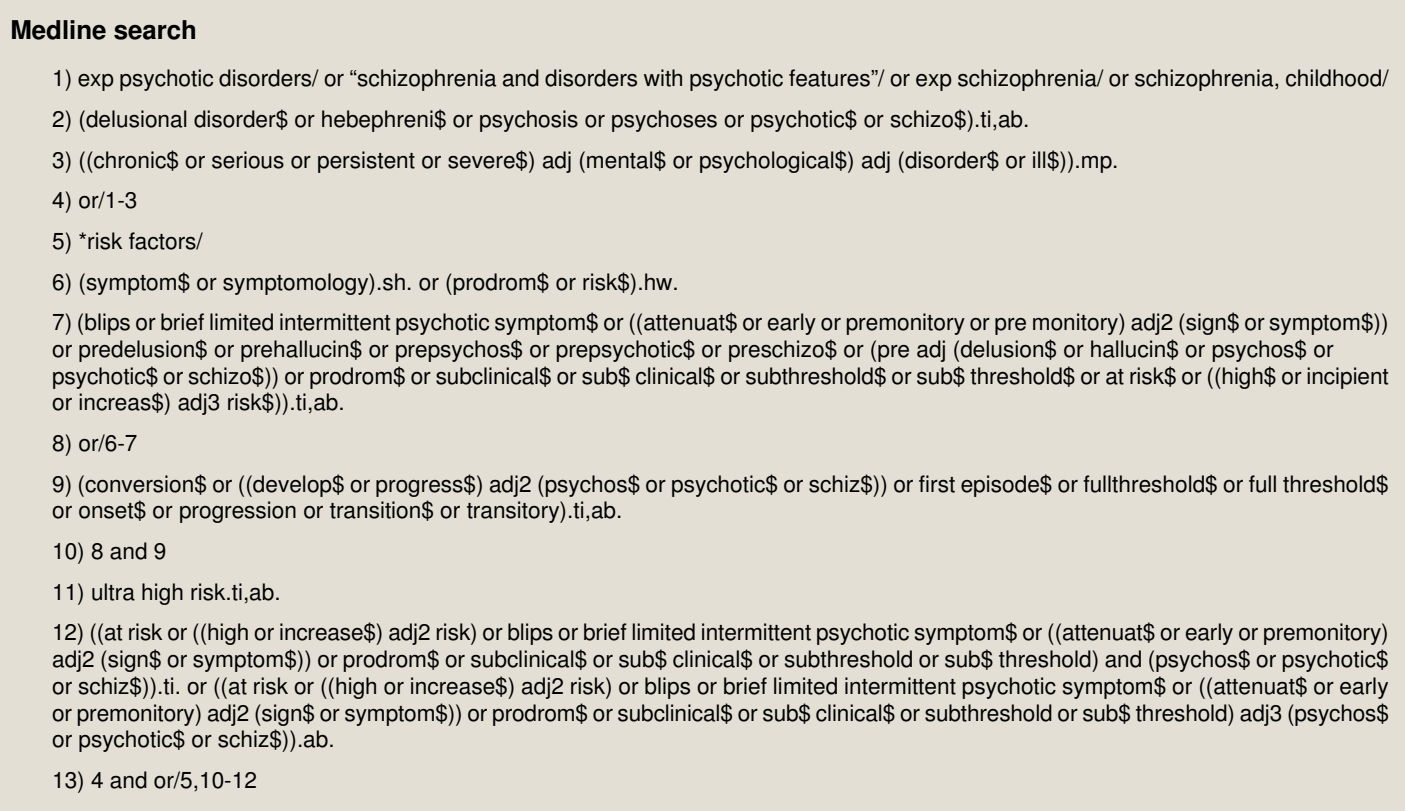

with placebo,[27] integrated therapies with supportive counselling,[37] integrated therapies with standard treatment,[35] omega-3 fatty acids with placebo,[26] and amisulpride plus a needs based intervention with the needs based intervention alone.[38]

Trials of CBT[23][24][25] [28][29][30] provided manualised, problem focused, time limited treatments including normalisation, cognitive restructuring, and behavioural experiments. Supportive counselling and monitoring[23][24][25] [28] [30] [37] were designed to match interventions for non-specific effects of treatment, and included psychoeducation, referral, and crisis management. "Treatment as usual" for participants currently seeking help for mental health problems occurred in mental health services[29] or at a community mental health centre.[35] Integrated psychological therapies included CBT for individual patients, group skills training, cognitive remediation, and family treatments, with concomitant antipsychotic treatment [35] or without treatment.[39] In one study, the needs based intervention included usual clinical management and could include psychoeducation, crisis intervention, family counselling, and assistance with education or work related difficulties.[38] Web appendix 3 provides a detailed description of the psychological interventions used in the included trials.

Transition to psychosis was defined in several ways, including ICD-10[34] diagnosis of psychotic disorder[35]; diagnosis of schizophrenia spectrum disorders[25] using the Diagnostic and Statistical Manual of Mental Disorders, fourth edition (DSM-IV)[40]; a measure developed by the authors[27]; PANSS[31] symptom severity[23] [26] and CAARMS[33] symptom severity[24] [28] [29]; and presence of positive psychotic symptoms.[30] One study assessed the transition from the early initial prodromal state to either the development of attenuated or transient symptoms (that is, subthreshold psychosis) or a DSM-IV psychotic disorder.[37]

\section{Risk of bias}

We rated risk of bias ratings for each trial (fig $2 \Downarrow$ ) using the Cochrane risk of bias tool.[41] No trials were at high risk of bias for sequence generation (not truly random), however, the method of randomisation was unclear (not reported) in three trials.[27] [30] [38] Risk of bias owing to poor allocation concealment was unclear in four trials.[25] [27] [30] [38] Lack of blinding of assessors created a high risk of bias for some outcomes in three studies.[30] [35] [38] Eight studies were at high risk of bias because participants or staff were not blind,[23] [25] [28][29][30] [35] [37] [38] which was impossible for studies of psychological interventions.

There was a high risk of bias due to incomplete outcome data for all included trials, which reflected a high rate of attrition in studies of this type of population rather than a methodological deficiency in the studies themselves.[6]

[23][24][25][26][27][28][29][30] [35] [37] [38]. In one study, some participants were not followed up for the last 12 months (that is, those entering in the final year of the study), and missing data could not be calculated on basis of the number of participants randomised.[28] Only four studies were clearly free of selective outcome reporting[23] [28] [29] [38]; three trials did not report all outcomes,[26] [35] [37] and it was unclear whether four trials reported all outcomes.[24] [25] [27] [30]

This review included several small studies of pharmacological and nutritional interventions. Because of small numbers, we were unable to assess publication bias formally - that is, using a trim and fill analysis[42] - but previous reviews have shown that studies of such interventions for children have been systematically under-reported in mental health, and that effects have been systematically overstated and harms systematically underestimated as a result.[43] Most of these interventions were developed before the introduction of mandatory trial registration,[44] rules with which manufacturers might fail to comply.[45] Because one or two small unpublished studies would be sufficient to change our view of the relative benefits and harms of these interventions, we considered that there was a high risk of publication bias.

\section{Quantitative data synthesis}

We conducted meta-analyses for eight comparisons. One trial with three treatment groups was included in three pairwise comparisons. [24] We analysed transition to psychosis (table $2 \Downarrow)$; symptoms of psychosis and depression; quality of life; dropout; and where possible, side effects (web appendix 4). Some evidence indicated that transition can be delayed (table 2) in trials of CBT,[23][24][25] [28] [29] CBT and risperidone,[30] integrated psychotherapy,[35] [37] and omega-3 
fatty acids.[26] However, confidence in these estimates ranged from moderate to very low.

\section{Psychological and complex psychosocial interventions}

Within the first six months of treatment, four studies comparing CBT with supportive counselling and monitoring [25] [28] [29] [46] reported that CBT did not reduce transition to psychosis (risk ratio 0.62 (95\% confidence interval 0.29 to 1.31 )). But trials included only 40 events (591 participants), and overall this evidence was of low quality. However, there was moderate quality evidence at 12 months indicating that more completers in the supportive counselling group transitioned to psychosis (0.54 (0.34 to 0.86$)$; fig $3 \Downarrow)$, which remained significant in sensitivity analysis $(0.64(0.44$ to 0.93$))$. At 18 months, there was low quality evidence that CBT is associated with fewer transitions (0.63 (0.40 to 0.99$))$, and the effect did not remain significant in sensitivity analysis $(0.55$ (0.25 to 1.19$))$.

Combined effects for positive symptoms of psychosis (fig $4 \Downarrow$ ), depression, and quality of life were not significant at any time point, but there was only low quality evidence for all outcomes except for positive symptoms within six and 12 months. One study[29] reported secondary outcomes only for participants who had not transitioned to psychosis; participants with the most severe symptoms were omitted from these analyses. In sensitivity analyses excluding this study, there was a significant effect for positive symptoms (standardised mean difference -0.27 (95\% confidence interval -0.47 to -0.06$)$ ), but effects for other outcomes remained non-significant. There was low quality evidence for total symptoms of psychosis and negative symptoms of psychosis, and effects were not significant.

Dropout rates were similar between groups within the first six months (risk ratio 1.09 (0.88 to 1.35$)$ ).

There was very low quality evidence for the benefits and harms associated with CBT and risperidone from two studies comparing $\mathrm{CBT}$ and risperidone with supportive counselling.[24] [30] Within the first six months of treatment, fewer people receiving CBT and risperidone transitioned to psychosis (risk ratio 0.35 (95\% confidence interval 0.13 to $0.95)$ ), but these trials included only 17 events (130 participants). The effect was no longer significant after 12 months $(0.63(0.33$ to 1.21$)$; fig $5 \Downarrow)$ or after 36 months $(0.59$ (0.34 to 1.04$))$. There were no significant effects of this treatment on quality of life, symptoms of psychosis (total, positive, or negative), depression, or mania. Within six months, there were no dropouts in one study,[30] and the dropout rate in the second study[24] was similar between groups (0.76 (0.28 to 2.03$))$.

There was evidence of very low quality for the benefits and harms associated with integrated psychotherapy from one study[39] comparing integrated psychotherapy (mean number of sessions 15.8 (standard deviation 6.8)) with supportive counselling (23.7 (13.1)) in participants in the early initial prodromal state.[37] This study measured transition to an ultra high risk or high risk mental state or a DSM-IV psychotic disorder. Within the first 12 months, fewer people completing integrated psychotherapy transitioned to an ultra high or high risk mental state or to psychosis (risk ratio 0.19 (95\% confidence interval 0.04 to 0.81$)$ ), but there were only 13 events ( 125 participants). The effect was maintained at 24 months $(0.32$ (0.11 to 0.92$)$ ). Dropout was similar between groups at 12 months (1.55 (0.68 to 3.53$)$ ) and 24 months (0.95 (0.61 to 1.49$)$ ).

There was low quality evidence from one study comparing integrated psychotherapies with standard treatment.[35] Within 12 months, fewer people receiving integrated psychotherapy transitioned to psychosis (risk ratio 0.24 (95\% confidence interval 0.07 to 0.81 )), but there were only 13 events (67 participants). The effect remained large when we assumed that dropouts transitioned $(0.41(0.20$ to 0.85$))$, but the effect was not quite significant after 24 months $(0.52$ (0.26 to 1.02)). There was no effect for positive or negative symptoms of psychosis at either time point. Dropout was similar between groups at 12 months (0.63 (0.22 to 1.81$))$ and 24 months (0.66 (0.25 to 1.73$))$.

\section{Pharmacological interventions}

One study compared CBT and risperidone with CBT and placebo.[24] Very low quality evidence within the first six months of treatment suggested no difference in transition to psychosis (risk ratio 1.02 (95\% confidence interval 0.15 to 6.94)), which remained at 12 months (1.02 (0.39 to 2.67)). Differences in symptoms of psychosis (total, positive, or negative), depression, and quality of life were not significant. Dropout was similar between groups (1.09 (0.62 to 1.92)), although the evidence was also rated as very low quality.

There was very low quality evidence for the benefits and harms associated with olanzapine, from one study comparing olanzapine with placebo.[27] We saw no difference in transition to psychosis after 12 months (risk ratio 0.44 (95\% confidence interval 0.17 to 1.08$)$ ). Dropout was similar between groups at 12 months (1.59 (0.88 to 2.88)). For participants taking olanzapine, there was a large effect on weight during the first eight weeks (standardised mean difference 0.81 (0.28 to 1.34)), which remained large at 12 months $(1.18(0.62$ to 1.73$))$. Effects on symptoms of psychosis (total, positive, or negative), depression, and mania were not significant. Data at 24 months were not analysed because fewer than $50 \%$ of participants remained.

We also found very low quality evidence for the benefits and harms associated with amisulpride, from one study comparing amisulpride and a needs based intervention with the needs based intervention alone.[38] Transition was not reported. Within six months, effects on total and negative symptoms of psychosis were not significant, but amisulpride was associated with a moderate reduction in positive symptoms (standardised mean difference -0.53 (95\% confidence interval -0.93 to -0.13$)$ ), and depression $(-0.51(-0.91$ to -0.11$))$. The addition of amisulpride was associated with a moderate reduction in dropout (risk ratio 0.59 (0.38 to 0.94$)$ ).

\section{Nutritional supplements}

We found low quality evidence for the benefits and harms associated with omega- 3 fatty acids, from one study comparing omega-3 fatty acids with placebo.[26] Participants received treatment for 12 weeks, which was associated with a large reduction in transition to psychosis after treatment (risk ratio 0.13 (95\% confidence interval 0.02 to 0.95$)$ ), but there were only nine events (76 participants). Assuming participants who dropped out transitioned to psychosis, the effect remained large at 12 weeks $(0.39$ (0.13 to 1.14$))$. This effect remained significant after 12 months $(0.18$ (0.04 to 0.75$))$, although the number of events was only 13 (81 participants). Treatment effects on total symptoms of psychosis (standardised mean difference $-1.26(-1.74$ to -0.78$)$ ), positive symptoms $(-2.08$ $(-2.63$ to -1.54$))$, negative symptoms $(-2.22(-2.77$ to -1.66$))$, and symptoms of depression $(-0.56(-1.01$ to -0.12$))$ also favoured omega- 3 fatty acids after 12 months. Dropouts at the end of treatment were not reported; however, dropout after 12 months was low and similar between groups (risk ratio 1.46 (0.26 to 8.30)). 


\section{Discussion}

\section{Comparison with other studies}

This systematic review and meta-analysis of treatments for people at high risk of developing psychosis included 11 trials and 1246 participants seeking treatment. Participants received a range of psychological, pharmacological, nutritional, and complex psychosocial interventions. This review included twice the number of studies and participants as a previous review, which did not find clear evidence of benefit.[14] Recent studies have contributed to a much larger dataset, which suggests that transition to psychosis from a high risk mental state could be preventable. These findings also suggest the future research strategies that are most likely to be fruitful, highlighting treatments that have the most potential for reducing transition to psychosis. On the basis of this review, further research is clearly warranted to determine the benefits of both psychological interventions - especially CBT with or without family treatment and a nutritional additive (omega-3 fatty acids).

\section{Summary of results}

Overall, five trials of CBT had a moderate effect on transition to psychosis at both 12 and 18 months. In sensitivity analyses, assuming dropouts had transitioned, the effect of CBT on transition remained significant at 12 months; however, the effect at 18 months was no longer significant. There has also been evidence that complex psychosocial interventions could reduce transition or delay onset of psychosis, relative to supportive counselling or treatment as usual. For omega-3 fatty acids, low quality evidence suggests a beneficial effect for a 12 week course of nutritional supplementation compared with placebo. However, the data emerged from a single trial with few participants, and this result has never been replicated to our knowledge. Although the absolute effects of treatments will vary across populations with different risks of psychosis at baseline (table $3 \Downarrow$ ), effects for the most promising interventions are likely to be clinically meaningful for many psychiatric services.

Although no other treatments showed any clear or reliable effects, most of the studies included in this review had several problems. Many trials were at an unclear risk of selection bias, and some trials were rated as having high risk of detection bias. We considered it unlikely that blinding of participants or providers would introduce any important bias, and we did not downgrade for this reason. It is possible to blind assessors in studies of psychological interventions, and we considered that any lack of assessor blinding could introduce bias and contribute to downgrading our quality assessment. Only four studies were clearly free of selective outcome reporting, with several studies not reporting all outcomes.

All identified trials were at a high risk of bias owing to incomplete outcome data; however, this result reflected a high rate of attrition in studies of this type of population rather than a methodological deficiency in the studies themselves. In addition, the definitions of prodromal, high risk, and ultra high risk mental states varied between studies. One study[37] used the development of subthreshold psychosis (or "ultra high risk" mental state, which was the entry criteria for most of the other studies) as part of their primary outcome. Although broadly similar, the different entry criteria and operational definitions of transition to psychosis could account for the overall transition rates being lower than expected; therefore, caution should be exercised when interpreting our results. Similarly,

epidemiological issues related to sampling, temporal fluctuation in symptoms, and risk enrichment strategies used in these trials, which would pose problems for the generalisability of these findings to routine healthcare settings.

Although most of the interventions used have some evidence for effectiveness in populations with frank psychosis, the included studies used different comparators, limiting comparisons between treatments and meta-analysis. Furthermore, control conditions that include active interventions could underestimate the effect of some interventions relative to no intervention. For example, comparisons included combinations of supportive counselling, regular and frequent monitoring of mental states, and treatment as usual. Consequently, transition at 12 months ranged from 7.1\%[28] to $27 \%$.[30] Additionally, $25 \%$ of participants in one study were inpatients at baseline,[35] suggesting an already ill population, perhaps even having already transitioned to psychosis, or representing people at high risk of self harm. Moreover, most studies recruited people who were seeking treatment, which necessarily omitted people who could benefit from help but did not seek it.

Our analyses were sensitive to assumptions about dropouts. Analyses of study completers suggest that psychological interventions (CBT with or without family intervention) have a beneficial effect; however, some findings were not significant when dropouts were assumed to have made transition. Since transition to psychosis is probably associated with service use, and most trials traced participants lost to follow-up via health records and family doctors, completer analyses (which are similar to analyses assuming that dropouts did not transition) might accurately represent participant outcomes. Because most outcomes were reported within one year, we considered the simple dichotomous outcome to be the best at measuring time to transition. Time to transition was measured and reported in several ways that would not facilitate a meaningful and transparent synthesis or a sensitivity analysis to test the importance of assumptions about dropouts.

\section{Strengths and limitations of study}

Our choice of primary outcome (dichotomous transition to psychosis) reflects the primary outcomes used in the clinical trials. However, it has been argued[47] that this crossing of a threshold is arbitrary and overemphasises the importance of positive symptoms, and that other dimensions might be more informative, such as negative symptoms, functioning, and quality of life. Therefore, we also analysed these outcomes, but fewer trials reported these variables and our analyses are probably underpowered as a result.

Importantly, we found no evidence to support the early promise of some antipsychotic drugs in delaying or preventing transition to psychosis. In addition, antipsychotic drugs are associated with clinically significant side effects. Although this is best described as an absence of evidence rather than evidence of absence, this review identifies no reason to pursue this line of enquiry. Many people at ultra high risk will not progress to psychosis, and we expect that any evidence indicating that the benefits outweigh the harms in this population would have been published. Furthermore, in a recent study of young people at risk of developing psychosis enrolled in a psychosocial treatment programme, significant clinical improvements were found without the use of antipsychotic drugs.[48]

Psychological treatments are also associated with significant side effects, with about $10 \%$ of participants in such treatments deteriorating,[49] [50] but psychological therapies are unlikely to cause the harms associated with antipsychotic drugs. Psychological treatment might be associated with an increase 
in stigma and other consequences for participants who would not develop psychosis even without treatment. Furthermore, there are ethical considerations in the delivery of all interventions for this population. Any future trials of psychological interventions should measure and report such adverse effects.

\section{Directions for future research}

The findings of this review do suggest two possible directions for future research. Firstly, the results of the trial using omega-3 fatty acids suggest that this intervention might have a beneficial effect on transition rates. A replication study with a larger sample is needed to determine whether this intervention has any merit. The use of omega- 3 fatty acids is a relatively safe treatment with few health risks that could have other potential benefits (such as for cardiovascular status).[51] Therefore, this intervention has particular appeal.

The second approach is based on the possible benefits from CBT, with or without family intervention. Good evidence indicates that family interventions are effective in reducing relapse rates in first episode psychosis and in established schizophrenia; and there is evidence that individual CBT has symptomatic benefit in both these contexts.[11] Preliminary evidence also indicates that cognitive therapy could benefit patients with first episode psychosis in the absence of antipsychotic drug treatment.[52] Moreover, the strongest evidence for prevention of recurrent psychotic episodes is for family interventions rather than individual CBT.[11] Transition from a high risk state to a first episode of psychosis might be susceptible to a treatment strategy combining family and individual CBT.

CBT may be particularly appropriate in light of the high prevalence of anxiety and mood disorders in this population.[28] [30] That is, guidelines for treatment of anxiety and depression recommend individual CBT, suggesting that $\mathrm{CBT}$ might also be helpful to patients who present in services but who will never transition to psychosis. Consideration of how to deliver these psychological interventions in an accessible and timely manner is required. Considerable investment would probably be needed in training therapists in this approach, or innovative methods need to be developed and evaluated. In the UK, it may be possible to incorporate this approach within the existing Increasing Access to Psychological Therapies programme, which has recently been extended to include children and young people as well as adults. To overcome some of the epidemiological issues outlined above, treatments could be embedded within a general staging model of mental healthcare. This model aims to deliver preventative, early interventions to young people in the hope of avoiding the development of more severe disorders.[53]

\section{Conclusions and policy implications}

Schizophrenia and the psychoses are highly disabling, recurrent, and most often lifelong conditions with substantial costs to the patient, their family, and the state - arguably greater than almost all other psychiatric conditions. The possible prevention of transition to psychosis and schizophrenia for people at high risk clearly represents an important finding.[54] Therefore, further research should be undertaken in the form of a large, multicentre trial of combined family and individual CBT for high risk groups, evaluating both benefits and potential harms (for example, possible increased stigma). In the meantime, the use of these psychological treatments now represents the most appropriate intervention available for helping people avert what could be a personal, social, and financial catastrophe.

Contributors: All authors contributed to the development of the review questions. MS and EMW drafted the protocol. Sarah Stockton of the National Collaborating Centre for Mental Health) designed and implemented the searches. MS, $\mathrm{HJ}$, and EMW assessed the eligibility of the studies for inclusion, extracted data, assessed risk of bias, and applied the GRADE criteria. All authors contributed to the analysis. All authors contributed to writing the manuscript, agreed on the final draft, had full access to the data (including statistical results and tables), and take responsibility for the integrity of the data and accuracy of the analysis. TK is the guarantor.

Funding: The National Collaborating Centre for Mental Health receives $£ 1.4$ million per year from the National Institute for Health and Clinical Excellence to develop guidelines for the treatment of mental health problems.

Competing interests: All authors have completed the Unified Competing Interest form at www.icmje.org/coi_disclosure.pdf (available on request from the corresponding author) and declare: support from the National Institute for Health and Clinical Excellence for the submitted work; TK is codirector of the National Collaborating Centre for Mental Health; this work was conducted as part of a guideline about psychosis in children and young people, and the full review protocol is available from the authors; AM was an author of two studies included in this review.

Ethical approval: None required.

Data sharing: No additional data available.

1 Bebbington P, Brugha T, Meltzer H, Farrell M, Ceresa C, Jenkins R, et al. Psychiatric disorder and dysfunction in the UK National Survey of Psychiatric Morbidity. Soc Psychiatry Psychiatr Epidemiol 2000;35:191-7.

2 Bebbington P, Brugha T, Coid J, Crawford M, Deverill C, D'Souza J, et al. Adult psychiatric morbidity in England, 2007. Results of a household survey. NHS Information Centre for Health and Social Care, 2011.

3 Mueser KT, McGurk SR. Schizophrenia. Lancet 2004;363:2063-72.

4 Bloom DE, Cafiero ET, Jané-Llopis E, Abrahams-Gessel S, Bloom LR, Fathima S, et al. The global economic burden of noncommunicable diseases. World Economic Forum, 2011. www3.weforum.org/docs/WEF_Harvard_HE

GlobalEconomicBurdenNonCommunicableDiseases 2011.pdf.

5 Mangalore R, Knapp M. Cost of schizophrenia in England. J Ment Health Policy Econ 2007;10:23-41.

6 McGlashan TH. Commentary: Progress, issues, and implications of prodromal research: an inside view. Schizophr Bull 2003;29:851-8.

7 Ruhrmann S, Schultze-Lutter F, Salokangas RK, Heinimaa M, Linszen D, Dingemans P, et al. Prediction of psychosis in adolescents and young adults at high risk: results from the prospective European prediction of psychosis study. Arch Gen Psychiatr 2010;67:241-51.

8 Yung AR, Phillips LJ, Yuen HP, Francey SM, McFarlane CA, Hallgren M, et al. Psychosis prediction: 12-month follow up of a high-risk ("prodromal") group. Schizophr Res 2003;60:21-32.

9 Miller TJ, McGlashan TH, Rosen JL, Somjee L, Markovich PJ, Stein K, et al. Prospective diagnosis of the initial prodrome for schizophrenia based on the Structured Interview for Prodromal Syndromes: preliminary evidence of interrater reliability and predictive validity. Am J Psychiatr 2002;159:863-5.

10 Fusar-Poli P, Bonoldi I, Yung AR, Borgwardt S, Kempton MJ, Valmaggia L, et al. Predicting psychosis: meta-analysis of transition outcomes in individuals at high clinical risk. Arch Gen Psychiatr 2012;69:220-9.

11 National Institute for Health and Clinical Excellence. The NICE guideline on core interventions in the treatment and management of schizophrenia in adults in primary and secondary care. Updated edition. NICE, 2009

12 Bird V, Premkumar P, Kendall T, Whittington C, Mitchell J, Kuipers E. Early intervention services, cognitive-behavioural therapy and family intervention in early psychosis: systematic review. Br J Psychiatry 2010;197:350-6.

13 McCrone P, Craig TK, Power P, Garety PA. Cost-effectiveness of an early intervention service for people with psychosis. Br J Psychiatry 2010;196:377-82.

14 Marshall M, Rathbone J. Early intervention for psychosis (review). Cochrane Database Syst Rev 2011;6:CD004718.

15 Higgins J, Green S. Cochrane handbook for systematic reviews of interventions version 5.0.1. Cochrane Collaboration, 2008.

16 Hedges LV. Statistical considerations. In: Cooper HM, Hedges LV, eds. The handbook of research synthesis. Russell Sage Foundation, 1994.

17 Greenland S, Robins JM. Estimation of a common effect parameter from sparse follow-up data. Biometrics 1985;41:55-68.

18 Mantel N, Haenszel W. Statistical aspects of the analysis of data from retrospective studies of disease. J Natl Cancer Inst 1959;22:719-48.

19 Higgins JP, Thompson SG. Quantifying heterogeneity in a meta-analysis. Stat Med 2002;21:1539-58.

20 Higgins JP, Thompson SG, Deeks JJ, Altman DG. Measuring inconsistency in meta-analyses. BMJ 2003;327:557-60.

21 Review manager (RevMan) version 5.0. Nordic Cochrane Centre, Cochrane Collaboration, 2008. 


\section{What is already known on this topic}

Schizophrenia is the most common psychosis and interferes with relationships, education, and occupational functioning

Schizophrenia is usually preceded by a prodromal period, and it has been shown that $22-44 \%$ of people at ultra high risk will transition to develop schizophrenia

Psychological or pharmacological interventions that delay or prevent transition from this prodromal period could be clinically and

economically important

\section{What this study adds}

This meta-analysis suggests that there are interventions that could prevent psychosis

Individual cognitive behavioural therapy, with or without family CBT, could be the most sensible first line treatment for people at a high risk

Further research is needed to establish the potential benefit of psychological interventions for people at high risk of psychosis

22 Atkins D, Best D, Briss PA, Eccles M, Falck-Ytter Y, Flottorp S, et al. Grading quality of evidence and strength of recommendations. BMJ 2004:328:1490.

23 Morrison AP, French P, Walford L, Lewis SW, Kilcommons A, Green J, et al. Cognitive therapy for the prevention of psychosis in people at ultra-high risk: randomised controlled trial. Br J Psychiatry 2004;185:291-7.

24 Phillips LJ, Nelson B, Yuen HP, Francey SM, Simmons M, Stanford C, et al. Randomized controlled trial of interventions for young people at ultra-high risk of psychosis: study design and baseline characteristics. Aus N ZJ Psychiatry 2009:43:818-29.

25 Addington J, Epstein I, Liu L, French P, Boydell KM, Zipursky RB. A randomized controlled trial of cognitive behavioral therapy for individuals at clinical high risk of psychosis. Schizophr Res 2011;125:54-61.

26 Amminger GP, Schafer MR, Papageorgiou K, Klier CM, Cotton SM, Harrigan SM, et al. Long-chain omega-3 fatty acids for indicated prevention of psychotic disorders: a randomized, placebo-controlled trial. Arch Gen Psychiatr 2010;67:146-54.

27 McGlashan TH, Zipursky RB, Perkins D, Addington J, Miller TJ, Woods SW, et al. The PRIME North America randomized double-blind clinical trial of olanzapine versus placebo in patients at risk of being prodromally symptomatic for psychosis. I. Study rationale and design. Schizophr Res 2003;61:7-18.

28 Morrison AP, Stewart SL, French P, Bentall RP, Birchwood M, Byrne R, et al. Early detection and intervention evaluation for people at high-risk of psychosis-2 (EDIE-2): trial rationale, design and baseline characteristics. Early Interv Psychiatry 2011;5:24-32.

29 van der Gaag M, Nieman D, Rietdijk J, Dragt S, Ising-Echergui H, Klaassen R, et al. Cognitive behavioural therapy for subjects at ultra-high risk for developing psychosis: a randomised controlled clinical trial. Schizophr Bull 2012. http://schizophreniabulletin. oxfordjournals.org/content/early/2012/08/30/schbul.sbs105.full.pdf?keytype=ref\& ijkey=tdJNazinP9pNhfR

30 McGorry PD, Yung AR, Phillips LJ, Yuen HP, Francey S, Cosgrave EM, et al. Randomized controlled trial of interventions designed to reduce the risk of progression to first-episode psychosis in a clinical sample with subthreshold symptoms. Arch Gen Psychiatr 2002;59:921-8.

31 Kay SR, Fiszbein A, Opler LA. The positive and negative syndrome scale (PANSS) for schizophrenia. Schizophr Bull 1987:13:261-76.

32 Overall JE, Donald RG. The brief psychiatric rating scale. Psychol Rep 1962;10:799-812.

33 Yung AR. The comprehensive assessment of at-risk mental states (CAARMS). University of Melbourne, 2000

34 World Health Organization. The ICD-10 classification of mental and behavioural disorders. Diagnostic criteria for research. WHO, 1993.

35 Nordentoft M, Petersen L, Jeppesen P, Thorup AA, Abel MB, Ohlenschlaeger J, et al. IOPUS: a randomised multicenter trial of integrated versus standard treatment for patients with a first-episode psychosis—secondary publication]. Ugeskrift Laeger 2006;168:381-4.

36 Hefner HBA. Early detection and intervention in psychosis. A practice handbook. Schattauer, 2011.

37 Bechdolf A, Wagner M, Ruhrmann S, Harrigan S, Putzfeld V, Pukrop R, et al. Preventing progression to first-episode psychosis in early initial prodromal states. Br J Psychiatry 2012;200:22-9.

38 Ruhrmann S, Bechdolf A, Kuhn KU, Wagner M, Schultze-Lutter F, Janssen B, et al. Acute effects of treatment for prodromal symptoms for people putatively in a late initial prodromal state of psychosis. Br J Psychiatry 2007;51(suppl):s88-95

39 Bechdolf A, Wagner M, Veith V, Ruhrmann S, Pukrop R, Brockhaus-Dumke A, et al. Randomized controlled multicentre trial of cognitive behaviour therapy in the early initia prodromal state: effects on social adjustment post treatment. Early Interv Psychiatry 2007:1:71-8.

40 American Psychiatric Association. Diagnostic and statistical manual of mental disorders, 4th edition. American Psychiatric Association, 1994.

41 Higgins JPT, Altman DG, Gøtzsche PC, Jüni P, Moher D, Oxman AD, et al. The Cochrane Collaboration's tool for assessing risk of bias in randomised trials. BMJ 2011:343.d5928.

42 Sutton AJ, Duval SJ, Tweedie RL, Abrams KR, Jones DR. Empirical assessment of effect of publication bias on meta-analyses. BMJ 2000;320:1574-7.

43 Whittington CJ, Kendall T, Fonagy P, Cottrell D, Cotgrove A, Boddington E. Selective serotonin reuptake inhibitors in childhood depression: systematic review of published versus unpublished data. Lancet 2004;363:1341-5.

44 Abbasi K. Compulsory registration of clinical trials. BMJ 2004;329:637-8.

45 Zarin DA, Ide NC, Tse T, Harlan WR, West JC, Lindberg DA. Issues in the registration of clinical trials. JAMA 2007;297:2112-20.

46 Yung AR, Nelson B. Young people at ultra high risk for psychosis: a research update. Early Interv Psychiatry 2011;5(suppl 1):52-7.

47 Fusar-Poli $\mathrm{P}$, van Os J. Lost in transition: setting the psychosis threshold in prodroma research. Acta Psychiatr Scand 2012, doi:10.1111/acps.12028.

48 Marshall C, Addington J, Epstein I, Lui L, Deighton S, Zipursky RB. Treating young individuals at clinical high risk for psychosis. Early Interv Psychiatry 2012;6:60-8.

49 Hansen NB, Lambert MJ, Forman EM. The psychotherapy dose-response effect and its implications for treatment delivery services. Clin Psychol Sci Pract 2002;9:329-43.
50 Lambet M. Presidential address: what we have learned from a decade of research aimed at improving psychotherapy outcome in routine care. Psychother Res 2007;17:1-14.

51 Freeman MP, Hibbeln JR, Wisner KL, Davis JM, Mischoulon D, Peet M, et al. Omega-3 fatty acids: evidence basis for treatment and future research in psychiatry. J Clin Psychiatry 2006;67:1954-67.

52 Morrison AP, French P, Stewart SLK, Birchwoord M, Fowler D, Gumley Al, et al. Early detection and intervention evaluation for people at risk of psychosis (EDIE-2): a multisite randomised controlled trial of cognitive therapy for at risk mental states. BMJ 2012;344:e2233.

53 McGorry P. Risk syndromes, clinical staging and DSM V: new diagnostic infrastructure for early intervention in psychiatry. Schizophr Res 2010;120:49-53.

54 McGlashan TH, Zipursky RB, Perkins D, Addington J, Miller T, Woods SW, et al. Randomized, double-blind trial of olanzapine versus placebo in patients prodromally symptomatic for psychosis. Am J Psychiatry 2006;163:790-9.

55 Miller TJ, Zipursky RB, Perkins D, Addington J, Woods SW, Hawkins KA, et al. The PRIME North America randomized double-blind clinical trial of olanzapine versus placebo in patients at risk of being prodromally symptomatic for psychosis. II. Baseline characteristics of the "prodromal" sample. Schizophr Res 2003;61:19-30.

56 Woods SW, Breier A, Zipursky RB, Perkins DO, Addington J, Miller TJ, et al. Randomized trial of olanzapine versus placebo in the symptomatic acute treatment of the schizophrenic prodrome. Biol Psychiatry 2003;54:453-64.

57 Phillips LJ, McGorry PD, Yuen HP, Ward J, Donovan K, Kelly D, et al. Medium term follow-up of a randomized controlled trial of interventions for young people at ultra high risk of psychosis. Schizophr Res 2007;96:25-33.

58 Morrison AP, Bentall RP, French P, Walford L, Kilcommons A, Knight A, et al. Randomised controlled trial of early detection and cognitive therapy for preventing transition to psychosis in high-risk individuals. Study design and interim analysis of transition rate and psychological risk factors. Br J Psychiatry 2002;43(suppl):s78-84.

59 Morrison AP, French P, Parker S, Roberts M, Stevens H, Bentall RP, et al. Three-year follow-up of a randomized controlled trial of cognitive therapy for the prevention of psychosis in people at ultrahigh risk. Schizophr Bull 2007;33:682-7.

60 Yung AR, Phillips LJ, Nelson B, Francey SM, PanYuen H, Simmons MB, et al. Randomized controlled trial of interventions for young people at ultra high risk for psychosis: 6-month analysis. J Clin Psychiatry 2011;72:430-40.

61 Rietdijk J, Dragt S, Klaassen R, Ising H, Nieman D, Wunderink L, et al. A single blind randomized controlled trial of cognitive behavioural therapy in a help-seeking population with an At Risk Mental State for psychosis: the Dutch Early Detection and Intervention Evaluation (EDIE-NL) trial. Trials 2010:11:30.

62 French P, Morrison AP. Early detection and cognitive therapy for people at high risk of developing psychosis. Wiley, 2004.

63 Beck AT. Cognitive therapy and the emotional disorders. International Universities Press, 1976.

64 Morrison AP. The interpretation of intrusions in psychosis: an integrative cognitive approach to hallucinations and delusions. Behav Cogn Psychother 2001;29:257-76.

65 Zubin J, Spring B. Vulnerability: a new view of schizophrenia. J Abnorm Psychol 1977;86:103-26.

66 Chadwick P, Birchwood M, Trower P. Cognitive therapy for delusions, voices and paranoia. John Wiley and Sons, 1996.

67 Fowler D, Garety P, Kuipers E. Cognitive behaviour therapy for psychosis: theory and practice. Wiley, 1995

68 Haddock G, Tarrier N, Spaulding W, Yusupoff L, Kinney C, McCarthy E. Individual cognitive-behavior therapy in the treatment of hallucinations and delusions: a review. Clin Psychol Rev 1998;18:821-38.

69 Kingdon DG, Turkington D. Cognitive-behavioural therapy for schizophrenia. Lawrence Erlbaum, 1994.

70 Larsen TK, Bechdolf A, Birchwood M. The concept of schizophrenia and phase specific treatment. Psychological treatment in pre-psychosis and non-responders. J Am Acad Psychoanal Dyn Psychiatr 2003;31:209-28.

71 Stein LI, Test MA. Alternative to mental hospital treatment I. Conceptual model, treatment program and clinical evaluation. Arch Gen Psychiatry 1980;31:37-42.

Accepted: 8 January 2013

\section{Cite this as: BMJ 2013;346:f185}

This is an open-access article distributed under the terms of the Creative Commons Attribution Non-commercial License, which permits use, distribution, and reproduction in any medium, provided the original work is properly cited, the use is non commercial and is otherwise in compliance with the license. See: http://creativecommons.org/licenses/bync/2.0/ and http://creativecommons.org/licenses/by-nc/2.0/legalcode. 


\section{Tables}

\begin{tabular}{|c|c|c|c|c|c|c|c|}
\hline Studies & Country & No & Screening instrument & $\begin{array}{l}\text { Participant age } \\
\text { (years, range) }\end{array}$ & Comparison & $\begin{array}{l}\text { Duration } \\
\text { (weeks) }\end{array}$ & $\begin{array}{l}\text { Follow-up } \\
\text { (weeks) }\end{array}$ \\
\hline Addington $2011^{25}$ & Canada & 51 & $\begin{array}{l}\text { Structured interview for } \\
\text { prodromal symptoms }\end{array}$ & 20.9 (NR) & CBT $v$ supportive counselling & 26 & 52 and 78 \\
\hline Amminger $2010^{14,26}$ & Austria & 81 & PANSS & 16.4 (NR) & $\begin{array}{l}\text { Omega } 3 \text { fatty acids }(1200 \mathrm{mg} / \text { day }) v \\
\text { placebo }\end{array}$ & 12 & 52 \\
\hline Bechdolf $2012^{37,39}$ & Germany & 128 & ERIraos & 25.8 (NR) & $\begin{array}{l}\text { Integrated therapies } v \text { supportive } \\
\text { counselling }\end{array}$ & 52 & 104 \\
\hline McGlashan $2003^{27,54-56}$ & US & 60 & $\begin{array}{l}\text { Structured interview for } \\
\text { prodromal symptoms }\end{array}$ & $17.8(12-36)$ & Olanzapine ( $8 \mathrm{mg} /$ day) $v$ placebo & 52 & 104 \\
\hline McGorry $2002^{30,57}$ & Australia & 59 & BPRS & $20(14-28)$ & $\begin{array}{l}\text { Risperidone ( } 1.3 \mathrm{mg} / \mathrm{day}) \text { and CBT } v \\
\text { supportive counselling }\end{array}$ & 26 & $156-208$ \\
\hline Morrison $2004^{23,58,59}$ & Great Britain & 60 & PANSS & $22(16-36)$ & $\begin{array}{l}\text { CBT and supportive counselling } v \\
\text { supportive counselling }\end{array}$ & 52 & 156 \\
\hline Morrison $2011^{28,52}$ & Great Britain & 288 & CAARMS & $20.7(14-34)$ & $\begin{array}{l}\text { CBT and supportive counselling } v \\
\text { supportive counselling }\end{array}$ & 26 & 104 \\
\hline Nordentoft $2006^{35}$ & Denmark & 79 & ICD-10 & 24.9 (NR) & $\begin{array}{l}\text { Integrated therapies } v \text { standard } \\
\text { treatment }\end{array}$ & 104 & NA \\
\hline Phillips $2009^{24,60}$ & Australia & 115 & CAARMS & $17.9(\mathrm{NR})$ & $\begin{array}{l}\text { Risperidone ( } 2 \mathrm{mg} / \text { day) and CBT } v \\
\text { CBT and placebo v supportive } \\
\text { counselling and placebo }\end{array}$ & 52 & 104 \\
\hline Ruhrmann $2007^{38}$ & Germany & 124 & $\begin{array}{l}\text { Early Recognition } \\
\text { Inventory (ERIraos) }\end{array}$ & $25.6(N R)$ & $\begin{array}{l}\text { Amisulpride (118.7 mg/day) and NBI } \\
v \mathrm{NBI}\end{array}$ & 12 & NA \\
\hline Van der Gaag $2012^{29,61}$ & Netherlands & 201 & CAARMS & $22.7(\mathrm{NR})$ & CBT $v$ supportive counselling & 26 & 52 and 78 \\
\hline
\end{tabular}




\begin{tabular}{|c|c|c|c|c|c|c|}
\hline Comparison & $\begin{array}{l}\text { Time point } \\
\text { (months of } \\
\text { treatment) }\end{array}$ & $\begin{array}{c}\text { No }(\%) \text { of trials in } \\
\text { analysis }\end{array}$ & $\begin{array}{l}\text { No (\%) of } \\
\text { participants in } \\
\text { analysis }\end{array}$ & $\begin{array}{c}\text { Risk ratio }(95 \% \mathrm{Cl}) \text {, random } \\
\text { effects }\end{array}$ & $\begin{array}{l}\text { Heterogeneity }\left(\mathrm{I}^{2}\right. \\
\left.(\%), \mathrm{X}^{2}(\mathrm{P})\right)\end{array}$ & $\begin{array}{l}\text { Quality of evidence } \\
\text { (GRADE) }\end{array}$ \\
\hline \multirow{3}{*}{$\begin{array}{l}\text { CBT } v \text { supportive } \\
\text { counseling }\end{array}$} & $0-6$ & $4(80)$ & $591(88)$ & $0.62(0.29$ to 1.31$)$ & $17,3.6(P=0.31)$ & Low* $\ddagger$ \\
\hline & $6-12$ & $5(100)$ & $645(71)$ & $0.54(0.34$ to 0.86$)$ & $\begin{array}{c}0,2.51(P=0.64) \\
=0 . P 2)\end{array}$ & Moderate $^{*}$ \\
\hline & $12+$ & $4(80)$ & $570(85)$ & 0.63 (0.40 to 0.99$)$ & $0,2.50(P=0.48)$ & Low $^{*} \ddagger$ \\
\hline \multirow{3}{*}{$\begin{array}{l}\text { CBT and } \\
\text { risperidone } v \\
\text { supportive } \\
\text { counselling } \\
\end{array}$} & $0-6$ & $2(100)$ & $130(100)$ & $0.35(0.13$ to 0.95$)$ & $0,0.59(P=0.44)$ & Very low ${ }^{\star} \ddagger \S$ \\
\hline & $6-12$ & $2(100)$ & $130(100)$ & $0.63(0.33$ to 1.21$)$ & $0,0.25(P=0.61)$ & Very low* $\neq \S$ \\
\hline & $12+$ & $1(50)$ & $41(32)$ & $0.59(0.34$ to 1.04$)$ & NA & Very low ${ }^{*} \ddagger \S$ \\
\hline \multirow{2}{*}{$\begin{array}{l}\text { Integrated } \\
\text { psychotherapy } v \\
\text { supportive } \\
\text { counselling }^{37} \\
\end{array}$} & $6-12$ & $1(100)$ & $125(100)$ & $0.19(0.04$ to 0.81$)$ & NA & Very low* $¥ \mathbb{I}$ \\
\hline & $12+$ & $1(100)$ & $125(100)$ & $0.32(0.11$ to 0.92$)$ & NA & Very low $\neq \rrbracket$ \\
\hline \multirow{2}{*}{$\begin{array}{l}\text { Integrated } \\
\text { psychotherapy } v \\
\text { standard care }^{35}\end{array}$} & $6-12$ & $1(100)$ & $67(85)$ & $0.24(0.07$ to 0.81$)$ & NA & Low $^{*} \ddagger$ \\
\hline & $12+$ & $1(100)$ & $65(82)$ & $0.52(0.26$ to 1.02$)$ & NA & Low $^{*} \ddagger$ \\
\hline \multirow{2}{*}{$\begin{array}{l}\mathrm{CBT} \text { and } \\
\text { risperidone } v \mathrm{CBT} \\
\text { and placebo }{ }^{24}\end{array}$} & $0-6$ & $1(100)$ & $87(100)$ & $1.02(0.15$ to 6.94$)$ & NA & Very low ${ }^{*} \ddagger \S$ \\
\hline & $6-12$ & $1(100)$ & $87(100)$ & $1.02(0.39$ to 2.67$)$ & NA & Very low $¥ \S$ \\
\hline $\begin{array}{l}\text { Olanzapine } v \\
\text { placebo }^{27}\end{array}$ & $6-12$ & $1(100)$ & $60(100)$ & $0.43(0.17$ to 1.08$)$ & NA & Very low* $¥ \S$ \\
\hline \multirow{2}{*}{$\begin{array}{l}\text { Omega } 3 \text { fatty } \\
\text { acids } v \text { placebo }{ }^{26}\end{array}$} & $0-6$ & $1(100)$ & $76(94)$ & $0.13(0.02$ to 0.95$)$ & NA & Low*\$ \\
\hline & $6-12$ & $1(100)$ & $81(100)$ & $0.18(0.04$ to 0.75$)$ & NA & Low ${ }^{*} \S$ \\
\hline
\end{tabular}

$\mathrm{NA}=$ not applicable; $\mathrm{NBI}=$ needs based intervention.

${ }^{*}$ Reason for downgrading: imprecision.

†Reason for downgrading: inconsistency.

‡Reason for downgrading: risk of bias.

§Reason for downgrading: risk of publication bias.

IReason for downgrading: indirectness. 
Table 3 | Absolute effects of treatments for patients at high risk and very high risk of developing psychosis. Data are number of participants per 1000 who will transition

Population Intervention Control

CBT (risk ratio $=0.54$ )

$\begin{array}{lll}\text { Very high risk } & 162 & 300\end{array}$

High risk $\quad 54 \quad 100$

CBT and risperidone (risk ratio $=0.63$ )

Very high risk $\quad 189 \quad 300$

High risk $63 \quad 100$

Integrated psychotherapy (risk ratio $=0.19$ )

Very high risk $\quad 57 \quad 300$

High risk $19 \quad 100$

Fish oil/omega- 3 fatty acids (risk ratio $=0.18$ )

Very high risk $\quad 54 \quad 300$

High risk $18 \quad 100$ 


\section{Figures}

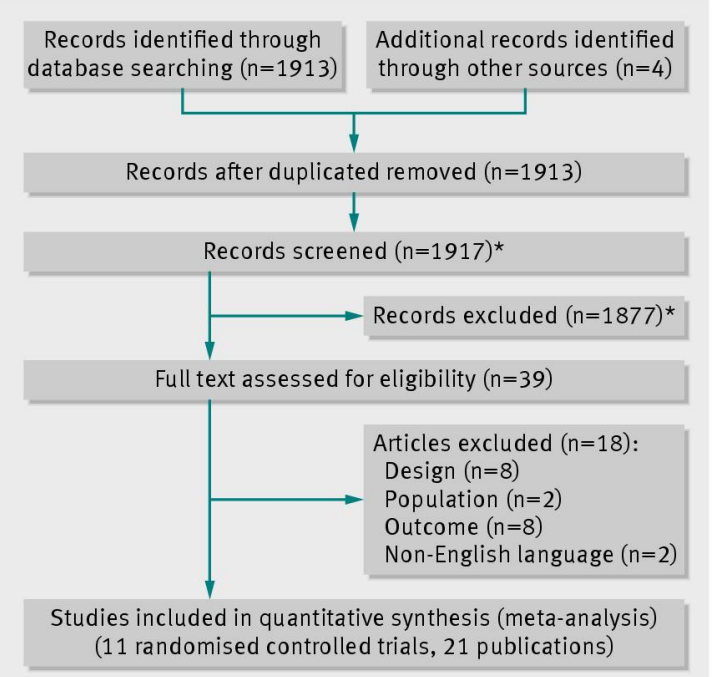

Fig 1 PRISMA flowchart. *Number of records screened for eligibility for the guideline in which the current work was a part 


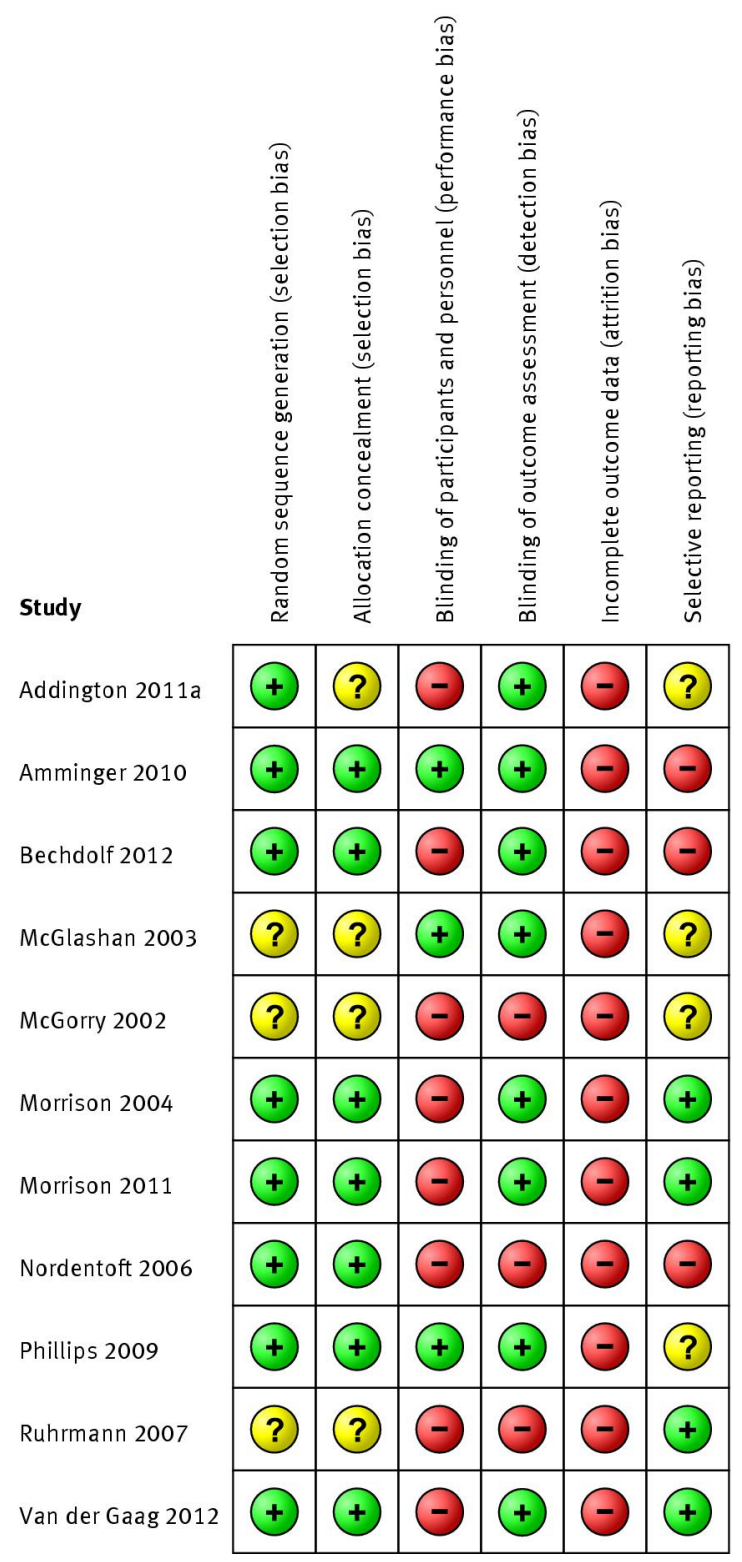

Fig 2 Risk of bias

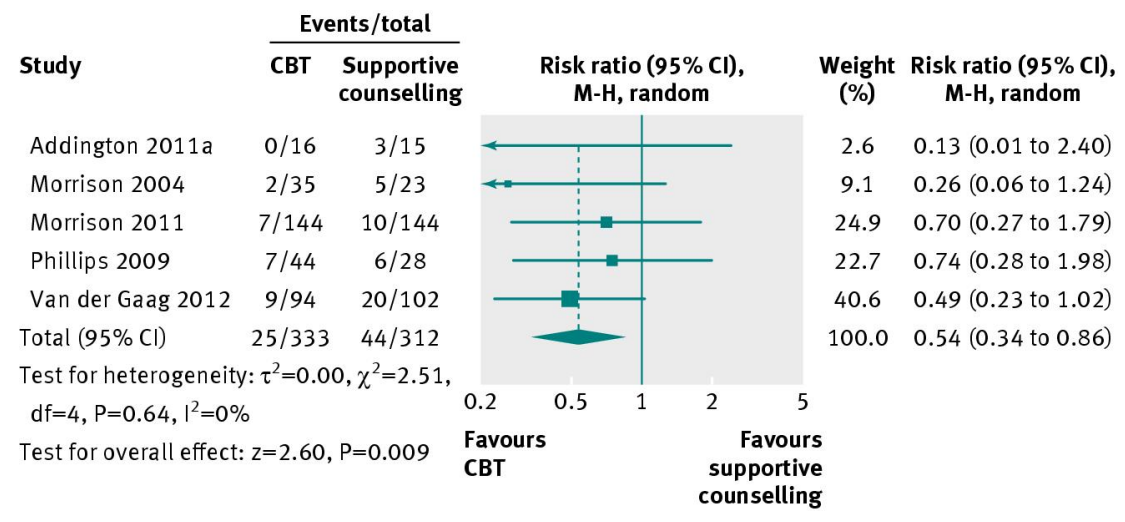

Fig 3 Transition to psychosis for participants receiving CBT versus supportive counselling, (at 6-12 months; includes completers only). M-H=Mantel-Haenszel 


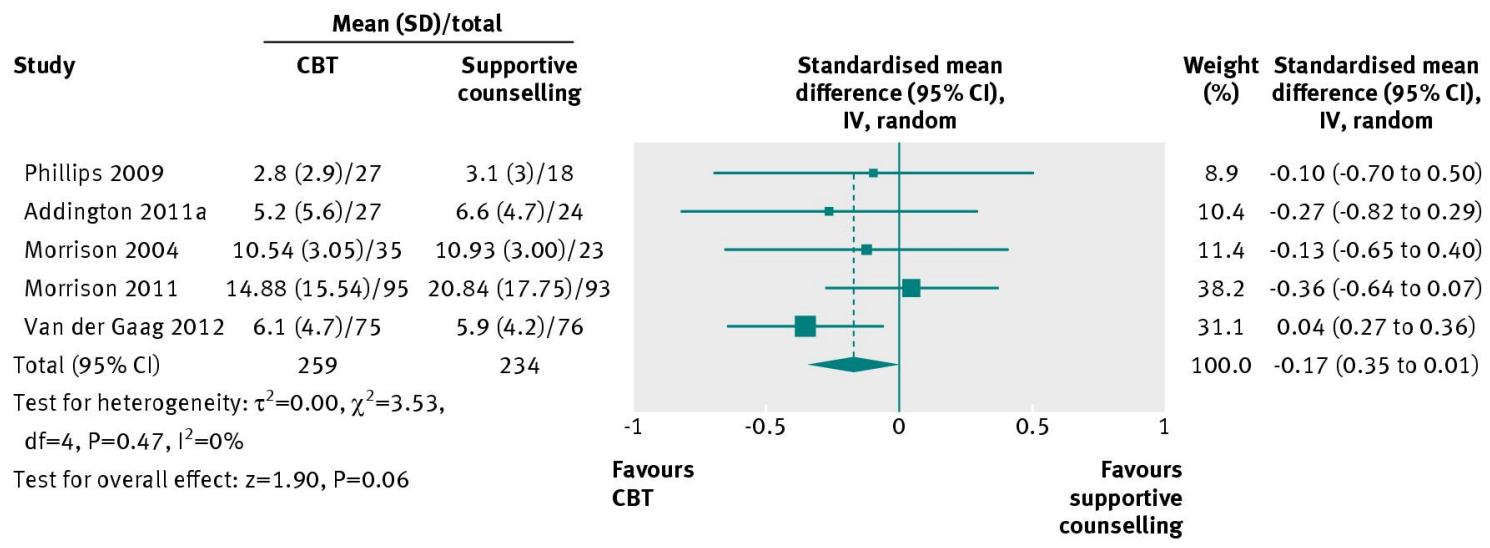

Fig 4 Positive symptoms of psychosis for participants receiving CBT versus supportive counselling (at 6-12 months). $\mathrm{IV}=$ inverse variance

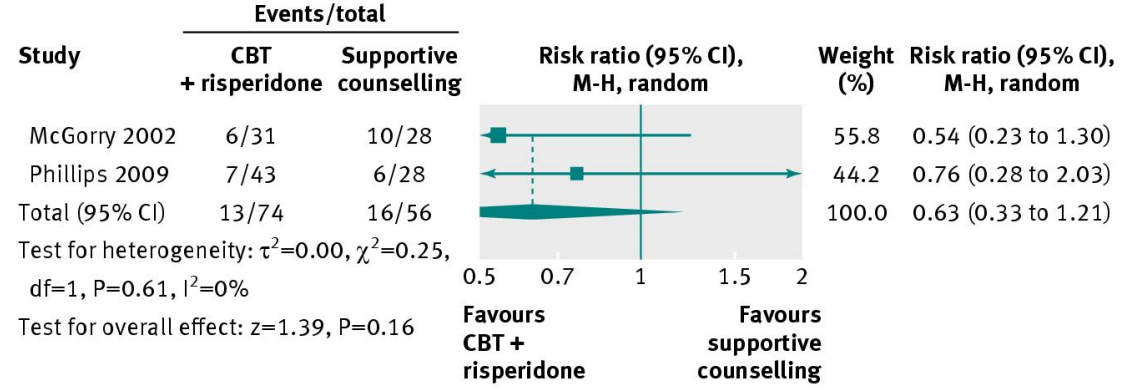

Fig 5 Transition to psychosis for participants receiving CBT and risperidone versus supportive counselling (at 6-12 months; includes completers only). $\mathrm{M}-\mathrm{H}=$ Mantel-Haenszel 